\title{
Mitochondrial dysfunction and insulin resistance: an update
}

\author{
Magdalene K Montgomery and Nigel Turner
}

Department of Pharmacology, UNSW Medicine, School of Medical Sciences, University of New South Wales, Kensington, Sydney, New South Wales 2052, Australia

Correspondence

should be addressed

to M K Montgomery

Email

m.montgomery@

unsw.edu.au

\begin{abstract}
Mitochondrial dysfunction has been implicated in the development of insulin resistance (IR); however, a large variety of association and intervention studies as well as genetic manipulations in rodents have reported contrasting results. Indeed, even 39 years after the first publication describing a relationship between $I R$ and diminished mitochondrial function, it is still unclear whether a direct relationship exists, and more importantly if changes in mitochondrial capacity are a cause or consequence of IR. This review will take a journey through the past and summarise the debate about the occurrence of mitochondrial dysfunction and its possible role in causing decreased insulin action in obesity and type 2 diabetes. Evidence is presented from studies in various human populations, as well as rodents with genetic manipulations of pathways known to affect mitochondrial function and insulin action. Finally, we have discussed whether mitochondria are a potential target for the treatment of IR.
\end{abstract}

\author{
Key Words \\ - mitochondrial function \\ - insulin resistance \\ - lipid accumulation \\ - oxidative stress \\ - mitophagy \\ - mitochondrial dynamics
}

\section{Mitochondrial function}

Mitochondria, originating from bacterial precursor cells that were able to generate energy, provide a platform for the generation of ATP, the energy currency of the cell. As ATP is essential for many cellular processes, mitochondrial function (and mitochondrial dysfunction) plays an important role in metabolic health and cellular fate. Mitochondrial function can be defined in a number of different ways, but for the purpose of this review we have largely focussed on the role of mitochondria in metabolic processes including oxidative phosphorylation and substrate oxidation (summarised in Fig. 1). The regulation of mitochondrial function is complex and still not fully understood. It involves rapid adaptations to changing metabolic conditions, such as fusion and fission, mitophagy as well as mitochondrial biogenesis. All of these will be discussed in the following sections, mainly in relation

http://www.endocrineconnections.org DOI: 10.1530/EC-14-0092 (c) 2015 The authors Published by Bioscientifica Ltd to changes in the obese state and under conditions of impaired insulin action (i.e. insulin resistance (IR)).

\section{Mitochondrial dysfunction}

The diverse roles of mitochondria in different cellular processes and the multitude of methods used to examine mitochondrial function have led to variations in the definition of 'mitochondrial dysfunction'. For example, mitochondrial function has been assessed by changes in mRNA levels of mitochondrial markers (either by targeted PCR or in more global microarray approaches) $(1,2,3,4)$, alterations in protein level (by immunoblotting) $(1,5)$ or in enzymatic activity of key components of mitochondriadriven oxidation $(1,6,7,8,9)$, as well as changes in mitochondrial size and shape (by electron microscopy) $(5,7,10)$ and substrate oxidation $(6,8)$. Accordingly, some groups referring to mitochondrial dysfunction as

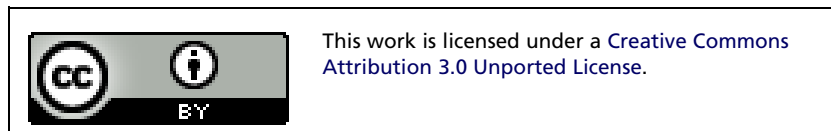




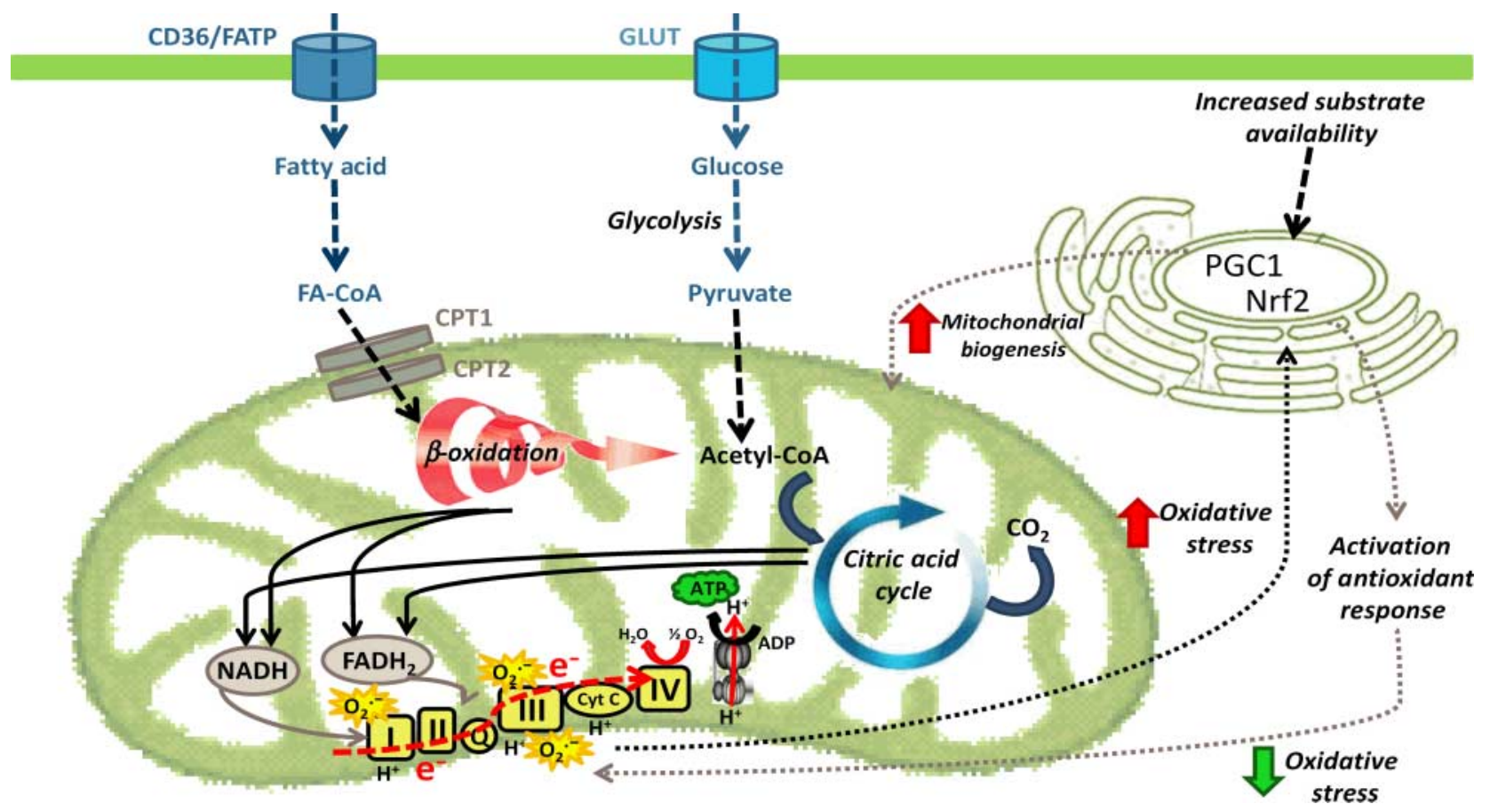

\section{Figure 1}

Fatty acids and glucose enter the cell via various membrane transporters. Fatty acids can either be converted to 'active' (DAG and ceramide) and 'inert' (TAG) lipid species or be transported into the mitochondria for oxidation to acetyl-CoA. Similarly, glucose can be metabolised to acetyl$\mathrm{CoA}$ in mitochondria. Acetyl-CoA entering the citric acid cycle produces

diminished mitochondrial content, others as a decrease in mitochondrial activity and oxidative phosphorylation, while others focus on different aspects such as reactive oxygen species (ROS) generation. In the context of this review, we refer to the term 'mitochondrial dysfunction' as a decrease in the mitochondrial oxidation of substrates, including lipid and carbohydrate, resulting from a general decrease in oxidative phosphorylation.

As well as defining mitochondrial dysfunction, it is important to give an overview about the possible mechanisms by which impairments in mitochondrial oxidative metabolism (i.e. mitochondrial dysfunction) could affect insulin sensitivity. Mitochondrial dysfunction can result from a decrease in mitochondrial biogenesis, reduced mitochondrial content and/or a decrease in the protein content and activity of oxidative proteins 'per unit of mitochondria' (such as a decrease in the complexes of the electron transport chain (ETC)) (Fig. 2). All such changes would presumably lead to a decrease in substrate oxidation (Fig. 2A). The reduced oxidation of fuels, particularly fatty acids, results in lipid accumulation, including deposition of metabolically active lipid reducing equivalents $\left(\mathrm{NADH}\right.$ and $\mathrm{FADH}_{2}$ ) that donate electrons for subsequent ATP generation in the electron transport chain. During electron transfer, superoxide $\left(\mathrm{O}_{2} \cdot{ }^{-}\right)$is generated, causing oxidative stress and potential induction of NRF2, and activation of antioxidant response elements to decrease oxidative stress levels.

mediators such as diacylglycerols (DAG) and ceramides (CER). Both DAG and CER have been shown to inhibit insulin signalling: DAG through protein kinase $\mathrm{C}$ activation translocates to the plasma membrane and inhibition of the insulin receptor (11), and CER through inhibition of the protein kinase AKT (Fig. 2C) $(12,13)$. DAG and CER accumulation is therefore a plausible link between mitochondrial dysfunction and IR. One potential caveat to this model is that muscle has an enormous spare respiratory capacity (i.e. oxygen consumption can increase ten to 20-fold above resting), and it has been proposed that a deficit in mitochondrial function of the magnitude observed in many obese and insulin-resistant individuals might not be expected to have major effects on substrate oxidation under resting conditions (14). However, it should be noted that in situations where muscle does dramatically increase respiration (e.g. exercise), there are typically large increases in muscle blood flow, marked changes in ATP demand, activation of multiple signalling pathways and large alterations in metabolite concentrations; in the absence of these changes (i.e. resting conditions), it is plausible that even relatively

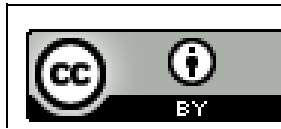

This work is licensed under a Creative Commons Attribution 3.0 Unported License. 


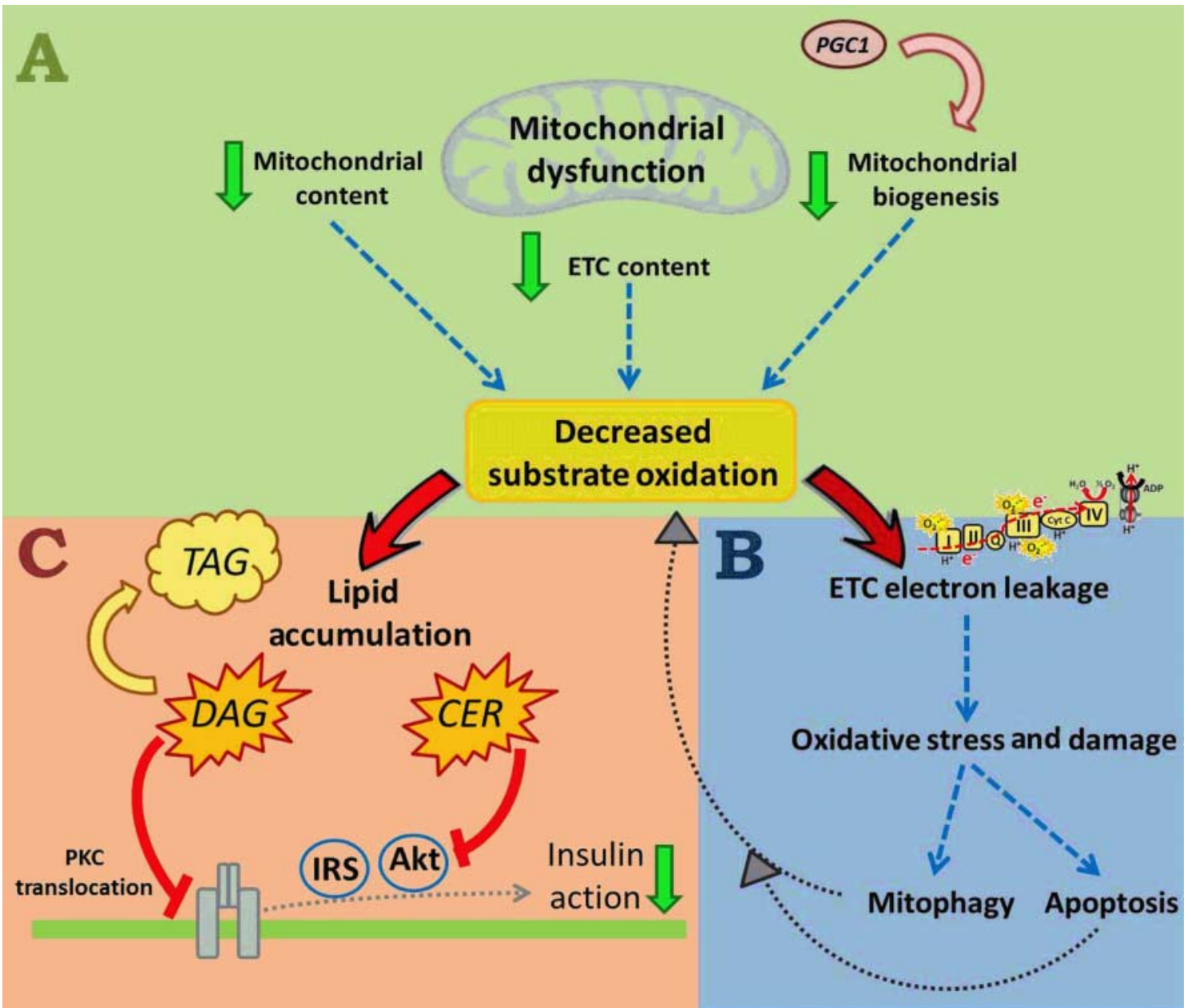

\section{Figure 2}

Mitochondrial dysfunction includes a reduction in mitochondrial content and mitochondrial biogenesis, and/or a decrease in the expression of mitochondrial oxidative proteins, such as complexes of the electron transport chain (ETC), with all those changes likely leading to decreased substrate oxidation (A). A diminished electron flow through the ETC can subsequently cause electron leakage and superoxide generation, followed by oxidative stress and damage. In a healthy environment, mitochondria

small decreases in substrate oxidation over time may partially lead to ectopic lipid accumulation and subsequently IR.

An additional potential mechanism linking mitochondrial dysfunction to IR is that decreases in substrate oxidation affect electron flow through the ETC, causing electron leakage towards oxygen and the formation of superoxide. Superoxide and other ROS damage various mitochondrial and cellular components (including oxidative damage to mitochondrial DNA, protein aggregations and lipid peroxidation), and potentially results in either mitophagy (removal of damaged mitochondria and prevention of cell death) or, under high stress levels, can respond to damage through mitophagy pathways (removal of damaged mitochondria, preventing cell death), or in the case of high cellular stress, with apoptosis (B), both aggravating the decrease in substrate utilisation, and all up leading to increased lipid accumulation (C). Active lipid intermediates, such as diacylglycerols (DAG) and ceramide (CER) then cause inhibition of the insulin signalling pathway.

apoptosis (Fig. 2B). Removal of mitochondria through mitophagy could reduce mitochondrial number, resulting in decreased substrate oxidation, further aggravating lipid accumulation.

\section{The debate about mitochondrial dysfunction and IR}

Mitochondrial dysfunction was first described in the context of glucose intolerance $\sim 40$ years ago (15), and the majority of studies in this area since that time have focussed on changes in skeletal muscle, which will be the main organ discussed in this review. Several studies in

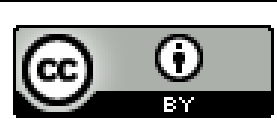

This work is licensed under a Creative Commons Attribution 3.0 Unported License. 
humans (from the late 1990s) suggested the existence of mitochondrial dysfunction in obese and insulin-resistant patients, with these individuals exhibiting lower oxidative enzyme activities and decreased lipid metabolism in muscle compared with lean control subjects $(6,8,9)$. In addition, Kelley et al. (7) published in 2002 that skeletal muscle of obese subjects with type 2 diabetes (T2D) exhibited lower NADH: $\mathrm{O}_{2}$ oxidoreductase activity and reduced mitochondrial size when compared with lean control subjects. One year later, two major microarray studies carried out in muscle showed mitochondrial biogenesis and oxidative phosphorylation pathways to be downregulated in T2D patients and non-diabetic individuals with a family history $(\mathrm{FH}+)$ of $\mathrm{T} 2 \mathrm{D}$ when compared with healthy controls $(2,3)$. These two studies were of particular interest to metabolic researchers as i) they showed a decrease in peroxisome proliferator coactivator 1a $(\mathrm{PGC} 1 \alpha)$, the master regulator of mitochondrial metabolism (Fig. 1), and therefore for the first time suggested a mechanism for the decrease in mitochondrial function, and ii) they provided evidence for genetic predisposition to mitochondrial defects and its occurrence in the 'pre-diabetic' state. Following these initial observations, several studies in humans showed similar downregulation of metabolic and mitochondrial pathways in obesity and IR (reviewed in (16 17)). Defects in the expression of mitochondrial genes were found at the mRNA level $(1,4,10,18)$ as well as at the protein level (1); this was accompanied by a decrease in oxidative enzyme activity $(1,5,7)$ and mitochondrial size and density $(5,7,10)$. To some extent, it still remains unclear whether the observed defects could be primarily due to a decrease in the number of mitochondria 'per unit of muscle tissue' or due to actual metabolic changes within the mitochondria $(19,20,21,22)$. Disparate results have also been reported with regards to the intramuscular populations of mitochondria that are affected (subsarcolemmal vs intermyofibrillar) $(5,23)$ and between different muscles across the body (24).

Although several human (as above) as well as rodent studies (25) have described associations between diminished mitochondrial function and obesity/IR, various independent publications have failed to show such a correlation. For example, several studies have shown that muscle mitochondrial function was not impaired in obese and T2D human subjects when compared with controls $(19,21,26,27)$. In addition, non-obese sedentary humans that were overfed for 28 days exhibited peripheral IR (determined as a decrease in glucose infusion rate during hyperinsulinemic-euglycaemic clamps) without changes in several markers of mitochondrial content in muscle (28). Similarly, rats fed a high-fat diet exhibited unchanged mRNA levels of various energy and glucose metabolism markers in muscle (29), as well as similar hepatic mitochondrial and peroxisomal fatty acid oxidation capacity when compared with low-fat diet controls (30).

Besides evidence for scenario 1 (a decrease in mitochondrial function with IR) and scenario 2 (unchanged mitochondrial function despite IR), several research groups, including ours, have shown a compensatory increase in mitochondrial oxidative capacity with increased lipid supply $(31,32,33,34)$. Mice and rats fed high-fat diets exhibited impairments in glucose tolerance and insulin sensitivity, but simultaneously an increase in fatty acid oxidative capacity, as well as protein content and activity of mitochondrial oxidative proteins in muscle $(31,32,33,34)$. Both the increase in mitochondrial content and oxidative capacity (35), as well as the development of IR (36), occur at around 3-4 weeks of high-fat feeding. Furthermore, in a recent comparison of mouse strain, our group showed that this mitochondrial adaptation to high-fat feeding was present in several different mouse strains (C57BL/6, 129X1, DBA/2 and $\mathrm{FVB} / \mathrm{N}$ ) that were prone to fat-induced obesity and glucose intolerance (37). The implications from these studies are that while there is a compensatory increase in mitochondrial oxidative capacity in rodents in response to dietary lipid oversupply, the timing and magnitude of these changes are not sufficient to cope with the dramatically enhanced lipid availability, and thus there is still ectopic lipid accumulation and IR. In support of this, dietary or genetic manipulations that enhance oxidative capacity in muscle above the normal adaptive response do ameliorate IR $(32,38,39)$.

Collectively, the three possible scenarios described above (i.e. decreased, unchanged or a compensatory increase in mitochondrial function) suggest that mitochondrial dysfunction is not a requisite feature of IR in all circumstances and the presence of mitochondrial dysfunction is dependent on its definition, the population studied, the model system examined (e.g. human vs rodent models) and the methodological approach (e.g. association vs intervention studies).

\section{Alterations of mitochondrial function: effects on insulin sensitivity}

As association studies of IR and mitochondrial function, as commonly reported for humans, are unable to delineate whether changes in mitochondrial function are a cause or

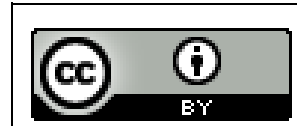

This work is licensed under a Creative Commons Attribution 3.0 Unported License. 
consequence of IR, various groups have relied on genetic manipulations and interventional approaches to define the cause-or-consequence question of whether changes in mitochondrial function have effects on tissue and wholebody insulin sensitivity. Various transgenic approaches have been taken to try to answer this question. As it is not possible to cover all of these studies, we will give examples of alterations in gene expression of three key metabolic regulators, TFAM, PGC1 and acetyl-CoA carboxylase 2 (ACC2), and discuss their effects on mitochondrial function and insulin sensitivity.

\section{TFAM}

Mitochondrial biogenesis is a complex process, involving a coordinated regulation of mitochondrial and nuclear genomes. An important protein controlling the transcription of mitochondrial proteins is the nuclear-encoded transcription factor TFAM, whose expression is regulated by nuclear respirator factor 1 (Nrf1) (40). Manipulating the gene expression of this key regulator of mitochondrial transcription is therefore an excellent approach to alter mitochondrial function. Muscle-specific Tfam-knockout mice exhibit abnormally appearing mitochondria in their muscles as well as progressively deteriorating respiratory chain function (41). Interestingly, ATP levels are almost unchanged due to a substantial increase in mitochondrial mass (41). In a subsequent study, the same researchers investigated glucose homeostasis in muscle-specific Tfamknockout mice and their results suggested that mitochondrial dysfunction in skeletal muscle is not a primary etiological event in the development of IR, as knockout mice exhibited improved glucose clearance during a glucose tolerance test and increased glucose uptake into muscle (likely due to increased expression of the glucose transporters GLUT1 and GLUT4 and increased AMPactivated protein kinase (AMPK) activity) (42). An independent group has recently created adipose tissue-specific Tfam-knockout mice, and their results are in line with the previous findings of Wredenberg et al. (43). As expected, Tfam-knockout mice exhibited decreased mtDNA copy number and diminished protein content of mitochondrially encoded proteins in brown and white adipose tissue, but displayed greater oxygen consumption due to higher uncoupling. Increased mitochondrial oxygen consumption resulted in elevated whole-body energy expenditure, which is a possible mechanism for these mice being protected against diet-induced obesity, glucose intolerance and lipid accumulation in their livers (43). Taken together, tissue-specific knockouts of TFAM indicate that experimentally inducing abnormalities in mitochondrial function does not necessarily lead to deterioration of glucose homeostasis and insulin sensitivity, highlighting a dissociation between IR and mitochondrial dysfunction.

\section{Peroxisome proliferator coactivator 1}

Although the knockout of TFAM demonstrated a clear dissociation between mitochondrial function and insulin sensitivity, alterations in gene expression of members of the PGC1 network have shown that metabolic downstream effects are variable, with complex compensatory interactions making interpretation of data difficult. $P G C 1 \alpha$ is a master-regulator of mitochondrial biogenesis, interacting with a large complement of transcription factors and nuclear hormone receptors that are associated with mitochondrial function (including $N r f 1, E R R \alpha, Y Y 1$, $P P A R \alpha, P P A R \gamma)$ (44). Global $P g c 1 \alpha$-knockout mice are viable; however they exhibit an abnormal energy metabolic phenotype. With age, $P g c 1 \alpha$-KO mice show an increase in whole-body as well as hepatic fat deposition, which is accompanied by a decrease in liver and muscle mitochondrial oxidative capacity. Surprisingly, KO mice were less susceptible to diet-induced IR than WT controls (45). Muscle-specific knockout of $P G C 1 \alpha$ also leads to increased fat mass; however in contrast, glucose tolerance was impaired in old mice (24 months), whereas it was unaltered in young (3 months) KO mice (46). This discrepancy between age groups may be explained by a compensatory increase in PGC1 $\beta$ in young, but not in aged mice (46). PGC1 $\alpha$ and PGC1 $\beta$ regulate a large number of overlapping genes, therefore metabolic compensation is not surprising. In addition to PGC1 $\alpha$ knockout, other studies have shown that also muscle-specific PGC1 $\alpha$ overexpression causes IR and glucose intolerance, potentially due to increased fatty acid delivery into muscle and decreased GLUT4 gene expression $(47,48)$. With these previous alterations of PGC1 protein levels, it should be noted that detrimental metabolic effects might be due to complicated adaptations due to life-long overexpression or knockout. In contrast, acute overexpression of PGC1 $\alpha$ and $P G C 1 \beta$ has shown that elevated PGC protein levels improve diet-induced IR in muscle $(38,49)$. Therefore, acute and targeted activation of PGC1-dependent pathways is likely to have therapeutic potential for the treatment of IR (50).

\section{Acetyl-CoA carboxylase 2}

As lipid oversupply is a major factor involved in the development of IR, a prevailing view was that increasing

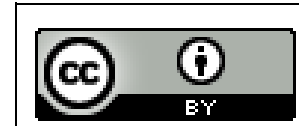

This work is licensed under a Creative Commons Attribution 3.0 Unported License. 
mitochondrial fatty acid oxidation would improve insulin sensitivity. Mitochondrial fatty acid oxidation is, in part, regulated by AMPK, which phosphorylates and inactivates the mitochondrial enzyme ACC2, leading to reduced malonyl-CoA levels, elevated CPT1 activity and increased entry of long-chain fatty acids into mitochondria for oxidation (51). In a recent report by Hoehn et al. (51) activation of AMPK by the AMP-mimetic aminoimidazole carboxamide ribonucleotide (AICAR), as well as global Acc2knockout in mice resulted in increased whole-body fatty acid oxidation. Interestingly, despite a significant increase in lipid oxidation, Acc2-knockout mice were not protected from high-fat diet-induced weight gain, glucose intolerance and deterioration of skeletal muscle glucose disposal, indicating that simply accelerating mitochondrial fatty acid oxidation alone does not prevent from a deterioration of insulin sensitivity (51). Similar observations were made by Olson et al. (52), who reported that selective deletion of Acc2 in mouse skeletal muscle, as well as inactivation in the germline had no effects on body weight, food intake, body composition or glucose homeostasis as compared with controls on chow or high-fat diet. These recent studies of unchanged skeletal muscle and whole-body insulin sensitivity in Acc2knockout mice contrast with earlier findings by Abu-Elheiga et al. (53), who reported that $A C C 2$ deletion leads to increased fat oxidation, reduced body weight and protection against diet-induced obesity and IR $(54,55,56)$. Phenotypic differences observed in these different lines of Acc2-knockout mice could potentially be due to multiple experimental differences (e.g. genetic background, diet composition and cloning strategy), but highlight that seemingly identical genetic manipulations can give contrasting results, complicating advances in our understanding on the importance of mitochondrial function in the development of IR.

In the section above, we have noted a number of examples emphasising that due to variable adaptations in different mouse lines, more direct genetic manipulation of mitochondrial function has still been unable to clearly define the impact of altering mitochondrial capacity on tissue and whole-body insulin sensitivity. However, since many insulin-resistant individuals do show mitochondrial defects, it is possible that the mitochondrial defects could be a consequence of reduced insulin action, which is discussed below.

\section{Regulation of mitochondrial function by insulin}

Insulin is an anabolic hormone that is known to play a major role in the regulation of metabolic pathways and protein synthesis in many tissues. A number of groups have examined the effect of insulin on mitochondrial function (largely via insulin infusions) and have also attempted to selectively alter glucose tolerance and insulin sensitivity in a previously 'metabolically healthy' environment to determine whether these changes affect mitochondrial function. The methodological approach taken for the latter has been to manipulate the components of the insulin signalling cascade to determine whether alterations directly affect insulin sensitivity (primary effect) and if changes in insulin sensitivity could potentially lead to alterations in mitochondrial capacity and function (secondary effect).

\section{Insulin infusions}

Insulin is known to affect various metabolic pathways in lipid and glucose metabolism, by either affecting gene expression or the phosphorylation of metabolic proteins $(57,58,59)$. In humans, several studies have also demonstrated direct effects of insulin to modify mitochondrial function, with insulin infusions leading to increased expression of mitochondrial proteins and higher oxidative enzyme activity and elevated ATP synthesis in muscle $(60,61)$. Further evidence of an effect of insulin on mitochondrial function came from a study by Karakelides et al. (62), who temporarily deprived type 1 diabetic patients of their insulin treatment and showed that insulin deficiency decreased muscle mitochondrial ATP production and expression of oxidative phosphorylation genes. This direct effect of insulin on mitochondrial function is diminished in subjects with IR (60) and in rats after high-fat feeding (63), suggesting that insulin is able to activate mitochondrial biogenesis and oxidative capacity, and that IR, particularly if it is present over a prolonged period, could in part contribute to mitochondrial dysfunction.

\section{Insulin receptor substrate gene manipulation}

With regards to direct genetic manipulation of insulin signalling components, the best characterised models have manipulated insulin receptor substrate (IRS) proteins. In skeletal muscle, selective disruption of IRS1 or IRS2 had only minor effects on insulin sensitivity, whereas simultaneous deletion of both members of the insulin signalling cascade had dramatic effects on insulin signalling and glucose tolerance (64). Isolated muscles exhibited complete resistance to insulin and diminished insulin-stimulated glucose uptake. In addition, the lack

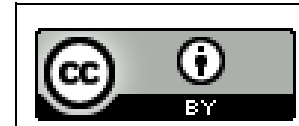

This work is licensed under a Creative Commons Attribution 3.0 Unported License. 
of insulin signalling in double-KO muscle impaired mitochondrial oxidative phosphorylation and ATP production (64)

In addition to the findings in skeletal muscle, similar mitochondrial impairments were also observed in hepatocytes lacking both IRS1 and IRS2 (65). Cheng et al. (65) also found larger deformed and 50\% fewer mitochondria in livers of these double-knockout (DKO) mice, with a simultaneous increase in markers of mitochondrial fission and fusion. Furthermore, many hepatic genes were deregulated in DKO livers, including genes known to control mitochondrial function, biogenesis and dynamics (65). Also, similar to the metabolic changes in skeletal muscle, selective silencing of IRS1 or IRS2 in liver had only minor effects on insulin signalling, whereas disruption of both isoforms led to impaired glucose tolerance and insulin sensitivity (66).

These results in muscle and liver suggest that direct genetic induction of IR has major effects on mitochondrial capacity, and that IR itself is able to lead to the development of mitochondrial dysfunction. Mitochondrial effects of $I R S 1 / 2$ deletion are likely mediated through the IRS-PI3K-Foxo pathway, as additional deletion of Foxo1 (triple knockout) was able to rescue the metabolic phenotype (65).

These studies of genetic manipulation of components of the insulin-signaling cascade, as well as direct insulin infusion or insulin deprivation, raise the possibility that mitochondrial defects observed in some insulin-resistant subjects could be a consequence of the IR itself.

\section{Ectopic lipid accumulation: effects on other mitochondrial parameters}

Ectopic lipid accumulation is commonly observed in obesity and T2D and is one of the earliest changes observed during the development of IR (36). Mitochondria respond to cellular stress (including excess lipid availability) in various ways, for example through increase in reactive species generation, complementation by fusion and fission and activation of cell death pathways. Interestingly, cells have developed a mechanism to sequester and degrade non-functional mitochondria, a process termed mitophagy, before cell death can occur. In this section, we will discuss scientific findings with regards to excess lipid availability and IR and the role of mitochondrial oxidative stress, mitophagy and stress mitigation through mitochondrial fusion and fission pathways.

\section{Oxidative stress}

Mitochondria are an important source of superoxide generation in the cell, with complexes I and III of the ETC having the greatest capacity for superoxide production (67). Most ROS within cells originate from superoxide and hydrogen peroxide, a product resulting from degradation of superoxide by the superoxide dismutase enzymes, or from biochemical reactions with these primary ROS (68). Under physiologically relevant ADP-stimulated conditions, mitochondrial superoxide represents only around $0.018 \%$ of total oxygen consumption (69), being therefore 'concentration-wise' a minor but 'implication-wise' a major player in mitochondrial function.

Several studies from the 1990s proposed a link between oxidative stress and the development of IR. Lipid infusions in humans increased plasma thiobarbituric acid reactive substance (TBARS) levels and simultaneously inhibited insulin-stimulated whole-body glucose disposal (70). In contrast, infusions of reduced glutathione exhibited the opposite effect on both oxidative damage and insulin sensitivity $(70,71)$.

More direct evidence connecting IR and mitochondrial ROS generation came from a recent study by Anderson et al. (72). In both rodents and humans, a highfat diet increased the $\mathrm{H}_{2} \mathrm{O}_{2}$-emitting potential of mitochondria without any changes in oxidative capacity. Attenuating mitochondrial $\mathrm{H}_{2} \mathrm{O}_{2}$ emission, by treating rats with a mitochondrial-targeted antioxidant or via overexpression of catalase in mouse muscle mitochondria, completely preserved glucose tolerance and insulin sensitivity (72). Similar beneficial effects for insulin action were observed when mitochondrial superoxide was reduced by genetic or pharmacological means (73). These and various other in vitro studies $(74,75)$ and genetic manipulations of antioxidant expression (e.g. targeted overexpression of catalase to mitochondria (76) or overexpression of mitochondrial peroxiredoxin 3 (77) highlight mitochondrial superoxide and $\mathrm{H}_{2} \mathrm{O}_{2}$ as a primary mechanism in the development of IR.

The studies noted above support a role for oxidative stress in the development of IR, and there have been a number of antioxidant supplementation trials which have reported that decreasing oxidative stress improves insulin sensitivity and glucose tolerance in various human populations $(78,79,80,81,82)$ and animal models $(83$, $84,85,86)$. However, it should be noted that there is still substantial controversy in this area, as various independent studies have failed to show such association. For example, antioxidant supplementation had minimal

This work is licensed under a Creative Commons Attribution 3.0 Unported License. 
impact on insulin sensitivity in various human populations $(87,88,89,90)$. Similarly, directed reduction in mitochondrial ROS generation using a mitochondriatargeted antioxidant did reduce oxidative stress levels in C2C12 myotubes as well as in mice, but did not affect glucose tolerance and insulin sensitivity (91).

These disparate findings suggest that depending on the experimental conditions, oxidative stress may be one of a number of factors contributing to IR. However, in circumstances where elevated mitochondrial ROS production is present during the development of IR, it is likely tightly coupled with autophagic removal of damaged mitochondria, a process termed mitophagy.

\section{Mitophagy}

Upon increased cellular and mitochondrial stress, mitochondria are able to activate both cell death pathways and mitophagy, with the two opposing forces in the cell, demonstrating a tight balance between life and death (92). The targeted removal of damaged mitochondria requires two steps: the initiation of autophagy and selective priming of mitochondria for removal (93). Priming is carried out by either the Pink1-Parkin pathway or through the activation of Nix and Bnip3 (94). Under metabolically healthy conditions, Pink1 is rapidly cleaved by mitochondrial proteases and degraded by the proteasome. However, upon loss of mitochondrial membrane potential Pink1 accumulates on the outer mitochondrial membrane and communicates with the E3 ubiquitin ligase Parkin. Parkin rapidly translocates to mitochondria and signals the initiation of mitophagy by ubiquinating mitochondrial proteins (VDAC1, mitofusin 1, mitofusin 2 and MIRO) (93). Furthermore, Parkin recruitment is suggested to be dependent on translocation of HSP72 to depolarised mitochondria, with HSP72-knockout mice exhibiting impaired Parkin action, enlarged and dysmorphic mitochondria, reduced muscle oxidative capacity, and muscle IR (95). This is one of few studies potentially suggesting mitophagy to be a beneficial metabolic event, important for the maintenance of mitochondrial quality and insulin sensitivity.

\section{Mitochondrial fusion and fission}

To maintain a metabolically healthy environment, removal of damaged mitochondria through mitophagy requires cells to be able to adapt quickly through changes in mitochondrial fusion and fission pathways. Mitochondria are dynamic organelles able to constantly undergo fusion and fission events to maintain their function (96). Fusion of mitochondria enables them to mix their contents, including mitochondrial DNA and metabolic intermediates, and to recover the activity of damaged or depolarised membranes (97). Mitochondrial fusion is predominantly controlled by three GTPases, mitofusin 1 and 2 (Mfn1/2), both located on the outer mitochondrial membrane, and optic atrophy1 (Opa1), localised on the inner membrane of mitochondria $(98,99)$. Fission on the other hand increases the number of mitochondria and prepares the cell for cell division and meiosis (100). It is regulated through the activity of Fis1, located throughout the outer membrane, and the dynamin-related protein 1 (DRP1). DRP1, lacking a mitochondrial targeting sequence, is usually located in the cytosol, but gets recruited to the mitochondrial outer membrane by Fis1 during the initiation of the fission process (101). Changes in mitochondrial dynamics could contribute to mitochondrial dysfunction observed in certain obese and insulin-resistant human and rodent populations. Skeletal muscle of obese and T2D humans and rodents shows reduced MFN2 expression (reviewed in (102)). Silencing of MFN2 in myotubes leads to decreased oxygen consumption and glucose oxidation (103, 104), with a simultaneous decrease in glucose incorporation into glycogen, as well as reductions in pyruvate and palmitate oxidation in myotubes (104). Changes in oxygen consumption and substrate oxidation with reduced MFN2 are likely due to a decrease in the expression of subunits of the electron transport complexes, which leads to reduced activity (102). These metabolic effects of MFN2 are independent of its role in mitochondrial fusion, as a mutant form of mitofusin 2, lacking the ability to induce fusion, was still able to stimulate energy metabolism (104). Decreased oxygen consumption and mitochondrial dysfunction were also observed in vivo in mice with simultaneous deletion of $M f n 1$ and $M f n 2$, which was suggested to be related with mtDNA depletion in early stages of life before physiological abnormalities developed (105). Interestingly, separate deletion of $M f n 1$ or $M f n 2$ did not result in any metabolic abnormalities (e.g. normal cytochrome c oxidase/succinate dehydrogenase (COX/SDH) histological staining pattern and no indication of respiratory deficiency), suggesting possible compensatory interactions between both isoforms (105). Due to the observed role of mitofusins in metabolism and their reported decrease in obesity and IR, these major regulators of mitochondrial dynamics are potentially important mediators of mitochondrial dysfunction. This is also supported by the fact that Mfn2 levels show a positive

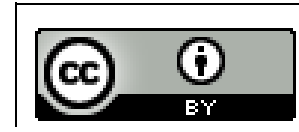

This work is licensed under a Creative Commons Attribution 3.0 Unported License. 
correlation with insulin sensitivity in morbidly obese subjects and after bariatric surgery $(106,107)$.

\section{Targeting mitochondria to treat obesity and IR}

As described in the preceding sections, there is substantial controversy on the exact role of mitochondria in the generation of IR. However, because of their role as the key site for substrate oxidation and ATP generation, targeting mitochondrial energy metabolism may has some benefit for metabolic disorders such as obesity and T2D. Below we discuss the evidence for various approaches (lifestyle interventions that affect mitochondrial oxidative metabolism and insulin action and more direct alterations of mitochondrial oxidative metabolism) aimed at improving aspects of mitochondrial function for potential therapeutic purposes. We also highlight the intriguing work showing that under certain circumstances, mild inhibition of mitochondrial function can also result in beneficial metabolic effects.

\section{Lifestyle interventions}

Exercise is known to have major impact on both mitochondrial function and insulin sensitivity in skeletal muscle. A 12-week exercise intervention programme in T2D patients significantly increased muscle mitochondrial respiration and mitochondrial content (108). Similarly, an 8-week cycling exercise regime increased muscle fatty acid oxidative capacity and in parallel improved insulinmediated glucose disposal (109). An improvement in insulin sensitivity and mitochondrial function (mitochondrial density and oxidative enzyme activity) was also reported by Toledo et al. (110) in T2D patients after 4 months of exercise training, by Nielson et al. (111) in male T2D subjects after 10 weeks of exercise, and by Meex et al. (112) in T2D patients after a 12-week exercise bout.

In addition to exercise, caloric restriction is an effective treatment improving obesity and IR. In obese humans, caloric restriction and weight loss were shown to improve insulin action $(113,114,115)$, reaching a $40 \%$ improvement in insulin sensitivity after 6 months of caloric restriction (116). Calorie restriction has also been reported to enhance mitochondrial function in humans (117). The $\mathrm{NAD}^{+}$-dependent deacetylase sirtuin 1 (SIRT1) is suggested to be the principal modulator of the downstream pathways responsible for the beneficial metabolic effects of calorie restriction $(118,119)$. In line with this, the SIRT1 activator resveratrol increases mitochondrial content, ameliorates IR and prolongs survival $(120,121)$. Recently, novel compounds have been characterised, which are 1000-fold more potent than resveratrol (122), with these compounds inducing a robust increase in mitochondrial content and respiration, which is associated with improved insulin sensitivity in mice $(123,124)$.

\section{Mitochondrial uncoupling}

The coupling of mitochondria describes the molar ratio of the yield of ATP (per oxygen consumed), also referred to as the $\mathrm{P} / \mathrm{O}$ ratio, while mitochondrial uncoupling is defined as futile cycling of protons across the mitochondrial inner membrane, without coupling to ATP generation (125). The inefficiency induced by mitochondrial uncoupling leads to increased energy expenditure and mitochondrial substrate oxidation, as well as improved insulin action $(126,127,128)$.

Pharmacological agents, such as 2,4-dintirophenol (DNP), can induce mitochondrial uncoupling by transporting protons across the mitochondrial inner membrane into the matrix. DNP was successfully used as an anti-obesity agent in the 1930s, suggesting that increased energy expenditure through mitochondrial uncoupling could have therapeutic potential (129). However, due to its narrow therapeutic window, overdoses led to serious imbalances of energy metabolism (and even to death), and DNP had to be taken off the market in 1938. More recently described uncoupling agents may potentially have a safer profile for use in humans $(130,131,132)$. For example, derivatives of rhodamine 19 were shown to reduce membrane potential and increase oxygen consumption. However, In contrast to DNP, the activity of those derivatives was highest at high membrane potentials and decreased with a loss of membrane potential, therefore exhibiting self-limitation and potentially being a safer option than DNP (130). In addition, Lou et al. (131) identified various mitochondrial uncouplers, that appear to act through the adenine nucleotide translocase and have a much greater therapeutic window than previously observed with DNP (dynamic range of 10(6)).

\section{Natural compounds}

Asian countries have a long history of using natural compounds for the treatment of metabolic disease. One of the compounds is Berberine, a natural plant alkaloid that was shown to improve insulin sensitivity in rodents and humans $(133,134)$. Interestingly, the effects of Berberine are not through enhancement of mitochondrial function

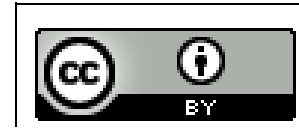

This work is licensed under a Creative Commons Attribution 3.0 Unported License. 
(as attempted with many other therapies), but appear to be through inhibition of complex I of the ETC, subsequent AMPK activation and the consequent beneficial metabolic effects (135). Interestingly, this counter-intuitive pattern of mild inhibition of mitochondrial oxidative metabolism has been reported in other insulin-sensitising medicinal plants (136) and is also a characteristic of metformin and thiazolidinediones, which are frontline anti-diabetic therapies $(135,137,138)$. While it is not completely resolved how mild, transient inhibition of mitochondrial function can lead to beneficial effects, it likely involves a number of mechanisms including reductions in deleterious lipid metabolites (due to decreased lipid synthesis and increased fatty acid oxidation following AMPK activation) and potentially decreases in ROS production (139). Increased fatty acid oxidation, despite a mild inhibition of complex I, is likely to occur due to AMPK-mediated lowering of malonyl-CoA levels and increased CPT1mediated fatty acid entry into mitochondria. Increased flux of fatty acids into $\beta$ oxidation generates both NADH and $\mathrm{FADH}_{2}$, with the entry of electrons into the ETC via complex II allowing substrate metabolism to continue despite a transient block at complex I. In addition, a decrease in ROS generation could be potentially mediated via reduced electron backflow and superoxide production from the ubiquinone reduction site of complex I with $\mathrm{FADH}_{2}$ (generated during each $\beta$ oxidation cycle) as the electron donor.

\section{Concluding remarks}

During the last 20 years, many studies have reported changes in mitochondrial function in various models of metabolic disease. Interestingly, these changes have been of opposing character, with some studies reporting a decrease in mitochondrial function (i.e. mitochondrial dysfunction), while others have reported either no change or an increase in mitochondrial oxidative metabolism in obese and insulin resistant humans and rodents. Similarly, studies using genetically manipulated mice to alter mitochondrial function have also produced confounding results. Collectively, these studies highlight that the relationship between mitochondria and insulin action is highly complex and there is still much to learn in this area. Some potential approaches for closing these gaps in knowledge in future studies include developing methods (e.g. with stable isotope tracers) to assess dynamic changes in mitochondrial function in vivo, not just in the typical fasting state, but also under a variety of other free-living conditions (e.g. in response to meals and during normal daily activities). Furthermore, increasing evidence of multiple post-translational modifications in mitochondria highlights that future studies in isolated mitochondria or tissue preparations must be performed in the presence of appropriate inhibitors to maintain the mitochondria in a similar state that observed in vivo. Studies such as these may help to more clearly define the extent to which mitochondrial dysfunction contributes to the development of IR, and also determine how effective targeting mitochondria may be for the treatment of IR.

\section{Declaration of interest}

The authors declare that there is no conflict of interest that could be perceived as prejudicing the impartiality of the review.

\section{Funding}

Work in the laboratory of the authors is supported by the National Health and Medical Research Council of Australia (NHMRC). M K Montgomery is supported by a NHMRC Early Career Fellowship (APP1071143) and N Turner by an Australian Research Council Future Fellowship (FT120100371).

\section{References}

1 Heilbronn LK, Gan SK, Turner N, Campbell LV \& Chisholm DJ. Markers of mitochondrial biogenesis and metabolism are lower in overweight and obese insulin-resistant subjects. Journal of Clinical Endocrinology and Metabolism 200792 1467-1473. (doi:10.1210/ jc.2006-2210)

2 Mootha VK, Lindgren CM, Eriksson KF, Subramanian A, Sihag S, Lehar J, Puigserver P, Carlsson E, Ridderstrale M, Laurila E et al. PGC- $1 \alpha$-responsive genes involved in oxidative phosphorylation are coordinately downregulated in human diabetes. Nature Genetics 2003 34 267-273. (doi:10.1038/ng1180)

3 Patti ME, Butte AJ, Crunkhorn S, Cusi K, Berria R, Kashyap S, Miyazaki Y, Kohane I, Costello M, Saccone R et al. Coordinated reduction of genes of oxidative metabolism in humans with insulin resistance and diabetes: potential role of PGC1 and NRF1. PNAS 2003100 8466-8471. (doi:10.1073/pnas.1032913100)

4 Skov V, Glintborg D, Knudsen S, Jensen T, Kruse TA, Tan Q, Brusgaard K, Beck-Nielsen H \& Højlund K. Reduced expression of nuclear-encoded genes involved in mitochondrial oxidative metabolism in skeletal muscle of insulin-resistant women with polycystic ovary syndrome. Diabetes 200756 2349-2355. (doi:10.2337/db07-0275)

5 Ritov VB, Menshikova EV, He J, Ferrell RE, Goodpaster BH \& Kelley DE. Deficiency of subsarcolemmal mitochondria in obesity and type 2 diabetes. Diabetes 200554 8-14. (doi:10.2337/diabetes.54.1.8)

6 Kelley DE, Goodpaster B, Wing RR \& Simoneau JA. Skeletal muscle fatty acid metabolism in association with insulin resistance, obesity, and weight loss. American Journal of Physiology 1999277 E1130-E1141.

7 Kelley DE, He J, Menshikova EV \& Ritov VB. Dysfunction of mitochondria in human skeletal muscle in type 2 diabetes. Diabetes 200251 2944-2950. (doi:10.2337/diabetes.51.10.2944)

8 Kim J-Y, Hickner RC, Cortright RL, Dohm GL \& Houmard JA. Lipid oxidation is reduced in obese human skeletal muscle. American Journal of Physiology. Endocrinology and Metabolism 2000279 E1039-E1044.

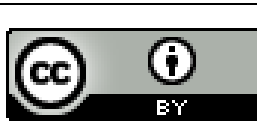

This work is licensed under a Creative Commons Attribution 3.0 Unported License. 
9 Simoneau J-A, Veerkamp JH, Turcotte LP \& Kelley DE. Markers of capacity to utilize fatty acids in human skeletal muscle: relation to insulin resistance and obesity and effects of weight loss. FASEB Journal 199913 2051-2060.

10 Morino K, Petersen KF, Dufour S, Befroy D, Frattini J, Shatzkes N, Neschen S, White MF, Bilz S, Sono S et al. Reduced mitochondrial density and increased IRS-1 serine phosphorylation in muscle of insulin-resistant offspring of type 2 diabetic parents. Journal of Clinical Investigation 2005115 3587-3593. (doi:10.1172/JCI25151)

11 Samuel VT, Petersen KF \& Shulman GI. Lipid-induced insulin resistance: unravelling the mechanism. Lancet 2010375 2267-2277. (doi:10.1016/S0140-6736(10)60408-4)

12 Bruce CR, Risis S, Babb JR, Yang C, Kowalski GM, Selathurai A, Lee-Young RS, Weir JM, Yoshioka K, Takuwa Y et al. Overexpression of sphingosine kinase 1 prevents ceramide accumulation and ameliorates muscle insulin resistance in high-fat diet-fed mice. Diabetes 2012 61 3148-3155. (doi:10.2337/db12-0029)

13 Schmitz-Peiffer C, Craig DL \& Biden TJ. Ceramide generation is sufficient to account for the inhibition of the insulin-stimulated PKB pathway in C2C12 skeletal muscle cells pretreated with palmitate. Journal of Biological Chemistry 1999274 24202-24210. (doi:10.1074/ jbc.274.34.24202)

14 Holloszy JO. Skeletal muscle "mitochondrial deficiency" does not mediate insulin resistance. American Journal of Clinical Nutrition 2009 89 463S-466S. (doi:10.3945/ajcn.2008.26717C)

15 Yamada T, Ida T, Yamaoka Y, Ozawa K, Takasan H \& Honjo I. Two distinct patterns of glucose intolerance in icteric rats and rabbits. Relationship to impaired liver mitochondria function. Journal of Laboratory and Clinical Medicine 197586 38-45.

16 Hwang H, Bowen BP, Lefort N, Flynn CR, De Filippis EA, Roberts C, Smoke CC, Meyer C, Højlund K, Yi Z et al. Proteomics analysis of human skeletal muscle reveals novel abnormalities in obesity and type 2 diabetes. Diabetes 201059 33-42. (doi:10.2337/db09-0214)

17 Turner $\mathrm{N} \&$ Heilbronn LK. Is mitochondrial dysfunction a cause of insulin resistance? Trends in Endocrinology and Metabolism 200819 324-330. (doi:10.1016/j.tem.2008.08.001)

18 Boyle KE, Canham JP, Consitt LA, Zheng D, Koves TR, Gavin TP, Holbert D, Neufer PD, Ilkayeva O, Muoio DM et al. A high-fat diet elicits differential responses in genes coordinating oxidative metabolism in skeletal muscle of lean and obese individuals. Journal of Clinical Endocrinology and Metabolism 201196 775-781. (doi:10.1210/ jc.2010-2253)

19 Bandyopadhyay GK, Yu JG, Ofrecio J \& Olefsky JM. Increased malonyl-CoA levels in muscle from obese and type 2 diabetic subjects lead to decreased fatty acid oxidation and increased lipogenesis; thiazolidinedione treatment reverses these defects. Diabetes 200655 2277-2285. (doi:10.2337/db06-0062)

20 Boushel R, Gnaiger E, Schjerling P, Skovbro M, Kraunsøe R \& Dela F. Patients with type 2 diabetes have normal mitochondrial function in skeletal muscle. Diabetologia 200750 790-796. (doi:10.1007/ s00125-007-0594-3)

21 Holloway GP, Thrush AB, Heigenhauser GJ, Tandon NN, Dyck DJ Bonen A \& Spriet LL. Skeletal muscle mitochondrial FAT/CD36 content and palmitate oxidation are not decreased in obese women. American Journal of Physiology. Endocrinology and Metabolism 2007292 E1782-E1789. (doi:10.1152/ajpendo.00639.2006)

22 Phielix E, Schrauwen-Hinderling VB, Mensink M, Lenaers E, Meex R, Hoeks J, Kooi ME, Moonen-Kornips E, Sels JP, Hesselink MK et al. Lower intrinsic ADP-stimulated mitochondrial respiration underlies in vivo mitochondrial dysfunction in muscle of male type 2 diabetic patients. Diabetes 200857 2943-2949. (doi:10.2337/db08-0391)

23 Chomentowski P, Coen PM, Radiková Z, Goodpaster BH \& Toledo FG. Skeletal muscle mitochondria in insulin resistance: differences in intermyofibrillar versus subsarcolemmal subpopulations and relationship to metabolic flexibility. Journal of Clinical Endocrinology and Metabolism 201196 494-503. (doi:10.1210/jc.2010-0822)
24 Rabøl R, Larsen S, Højberg PM, Almdal T, Boushel R, Haugaard SB, Andersen JL, Madsbad S \& Dela F. Regional anatomic differences in skeletal muscle mitochondrial respiration in type 2 diabetes and obesity. Journal of Clinical Endocrinology and Metabolism 201095 857-863. (doi:10.1210/jc.2009-1844)

25 Iossa S, Lionetti L, Mollica MP, Crescenzo R, Botta M, Barletta A \& Liverini G. Effect of high-fat feeding on metabolic efficiency and mitochondrial oxidative capacity in adult rats. British Journal of Nutrition 200390 953-960. (doi:10.1079/BJN2003000968)

26 Trenell MI, Hollingsworth KG, Lim EL \& Taylor R. Increased daily walking improves lipid oxidation without changes in mitochondrial function in type 2 diabetes. Diabetes Care 200831 1644-1649. (doi:10.2337/dc08-0303)

27 van Tienen FH, Praet SF, de Feyter HM, van den Broek NM, Lindsey PJ, Schoonderwoerd KG, de Coo IF, Nicolay K, Prompers JJ, Smeets HJ et al. Physical activity is the key determinant of skeletal muscle mitochondrial function in type 2 diabetes. Journal of Clinical Endocrinology and Metabolism 201297 3261-3269. (doi:10.1210/ jc.2011-3454)

28 Samocha-Bonet D, Campbell LV, Mori TA, Croft KD, Greenfield JR, Turner N \& Heilbronn LK. Overfeeding reduces insulin sensitivity and increases oxidative stress, without altering markers of mitochondrial content and function in humans. PLoS ONE 20127 e36320. (doi:10.1371/journal.pone.0036320)

29 Sreekumar R, Unnikrishnan J, Fu A, Nygren J, Short KR, Schimke J, Barazzoni R \& Nair KS. Impact of high-fat diet and antioxidant supplement on mitochondrial functions and gene transcripts in rat muscle. American Journal of Physiology. Endocrinology and Metabolism 2002282 E1055-E1061. (doi:10.1152/ajpendo.00554.2001)

30 Iossa S, Lionetti L, Mollica MP, Crescenzo R, Barletta A \& Liverini G. Effect of long-term high-fat feeding on energy balance and liver oxidative activity in rats. British Journal of Nutrition 200084 377-385. (doi:10.1017/S0007114500001665)

31 Turner N, Bruce CR, Beale SM, Hoehn KL, So T, Rolph MS \& Cooney GJ. Excess lipid availability increases mitochondrial fatty acid oxidative capacity in muscle: evidence against a role for reduced fatty acid oxidation in lipid-induced insulin resistance in rodents. Diabetes 200756 2085-2092. (doi:10.2337/db07-0093)

32 Turner N, Hariharan K, TidAng J, Frangioudakis G, Beale SM, Wright LE, Zeng XY, Leslie SJ, Li JY, Kraegen EW et al. Enhancement of muscle mitochondrial oxidative capacity and alterations in insulin action are lipid species dependent: potent tissue-specific effects of medium-chain fatty acids. Diabetes 200958 2547-2554. (doi:10.2337/ db09-0784)

33 de Wilde J, Mohren R, van den Berg S, Boekschoten M, Dijk KW, de Groot P, Müller M, Mariman E \& Smit E. Short-term high fat-feeding results in morphological and metabolic adaptations in the skeletal muscle of C57BL/6J mice. Physiological Genomics 200832 360-369. (doi:10.1152/physiolgenomics.00219.2007)

34 Garcia-Roves P, Huss JM, Han D-H, Hancock CR, Iglesias-Gutierrez E, Chen M \& Holloszy JO. Raising plasma fatty acid concentration induces increased biogenesis of mitochondria in skeletal muscle. PNAS 2007 104 10709-10713. (doi:10.1073/pnas.0704024104)

35 Hancock CR, Han D-H, Chen M, Terada S, Yasuda T, Wright DC \& Holloszy JO. High-fat diets cause insulin resistance despite an increase in muscle mitochondria. PNAS 2008105 7815-7820. (doi:10.1073/ pnas.0802057105)

36 Turner N, Kowalski GM, Leslie SJ, Risis S, Yang C, Lee-Young RS, Babb JR, Meikle PJ, Lancaster GI, Henstridge DC et al. Distinct patterns of tissue-specific lipid accumulation during the induction of insulin resistance in mice by high-fat feeding. Diabetologia 201356 1638-1648. (doi:10.1007/s00125-013-2913-1)

37 Montgomery MK, Hallahan NL, Brown SH, Liu M, Mitchell TW, Cooney GJ \& Turner N. Mouse strain-dependent variation in obesity and glucose homeostasis in response to high-fat feeding. Diabetologia 201356 1129-1139. (doi:10.1007/s00125-013-2846-8)

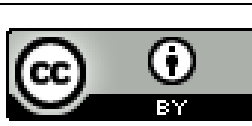


38 Wright LE, Brandon AE, Hoy AJ, Forsberg GB, Lelliott CJ, Reznick J, Lofgren L, Oscarsson J, Stromstedt M, Cooney GJ et al. Amelioration of lipid-induced insulin resistance in rat skeletal muscle by overexpression of Pgc-1 $\beta$ involves reductions in long-chain acyl-CoA levels and oxidative stress. Diabetologia 201154 1417-1426. (doi:10.1007/ s00125-011-2068-x)

39 Henstridge DC, Bruce CR, Drew BG, Tory K, Kolonics A, Estevez E, Chung J, Watson N, Gardner T, Lee-Young RS et al. Activating HSP72 in rodent skeletal muscle increases mitochondrial number and oxidative capacity and decreases insulin resistance. Diabetes 2014 63 1881-1894. (doi:10.2337/db13-0967)

40 Virbasius JV \& Scarpulla RC. Activation of the human mitochondrial transcription factor A gene by nuclear respiratory factors: a potential regulatory link between nuclear and mitochondrial gene expression in organelle biogenesis. PNAS 199491 1309-1313. (doi:10.1073/pnas.91. 4.1309)

41 Wredenberg A, Wibom R, Wilhelmsson H, Graff C, Wiener HH, Burden SJ, Oldfors A, Westerblad H \& Larsson N-G. Increased mitochondrial mass in mitochondrial myopathy mice. PNAS 2002 99 15066-15071. (doi:10.1073/pnas.232591499)

42 Wredenberg A, Freyer C, Sandström ME, Katz A, Wibom R, Westerblad $\mathrm{H} \&$ Larsson N-G. Respiratory chain dysfunction in skeletal muscle does not cause insulin resistance. Biochemical and Biophysical Research Communications 2006350 202-207. (doi:10.1016/j.bbrc.2006.09.029)

43 Vernochet C, Mourier A, Bezy O, Macotela Y, Boucher J, Rardin MJ, An D, Lee KY, Ilkayeva OR, Zingaretti CM et al. Adipose-specific deletion of TFAM increases mitochondrial oxidation and protects mice against obesity and insulin resistance. Cell Metabolism 2012 16 765-776. (doi:10.1016/j.cmet.2012.10.016)

44 Scarpulla RC. Metabolic control of mitochondrial biogenesis through the PGC-1 family regulatory network. Biochimica et Biophysica Acta 20111813 1269-1278. (doi:10.1016/j.bbamcr.2010.09.019)

45 Leone TC, Lehman JJ, Finck BN, Schaeffer PJ, Wende AR, Boudina S, Courtois M, Wozniak DF, Sambandam N, Bernal-Mizrachi C et al. PGC- $1 \alpha$ deficiency causes multi-system energy metabolic derangements: muscle dysfunction, abnormal weight control and hepatic steatosis. PLoS Biology 20053 e101. (doi:10.1371/journal.pbio. 0030101)

46 Sczelecki S, Besse-Patin A, Abboud A, Kleiner S, Laznik-Bogoslavski D, Wrann CD, Ruas JL, Haibe-Kains B \& Estall JL. Loss of Pgc- $1 \alpha$ expression in aging mouse muscle potentiates glucose intolerance and systemic inflammation. American Journal of Physiology. Endocrinology and Metabolism 2014306 E157-E167. (doi:10.1152/ajpendo. 00578.2013)

47 Choi CS, Befroy DE, Codella R, Kim S, Reznick RM, Hwang Y-J, Liu Z-X, Lee H-Y, Distefano A, Samuel VT et al. Paradoxical effects of increased expression of PGC-1 $\alpha$ on muscle mitochondrial function and insulinstimulated muscle glucose metabolism. PNAS 2008105 19926-19931. (doi:10.1073/pnas.0810339105)

48 Miura S, Kai Y, Ono M \& Ezaki O. Overexpression of peroxisome proliferator-activated receptor $\gamma$ coactivator- $1 \alpha$ down-regulates GLUT4 mRNA in skeletal muscles. Journal of Biological Chemistry 2003278 31385-31390. (doi:10.1074/jbc.M304312200)

49 Benton CR, Holloway GP, Han XX, Yoshida Y, Snook LA, Lally J, Glatz JF, Luiken JJ, Chabowski A \& Bonen A. Increased levels of peroxisome proliferator-activated receptor $\gamma$, coactivator $1 \alpha$ (PGC-1 $\alpha$ ) improve lipid utilisation, insulin signalling and glucose transport in skeletal muscle of lean and insulin-resistant obese Zucker rats. Diabetologia 201053 2008-2019. (doi:10.1007/s00125-010-1773-1)

50 Zhang L-N, Zhou H-Y, Fu Y-Y, Li Y-Y, Wu F, Gu M, Wu L-Y, Xia C-M, Dong T-C, Li J-Y et al. Novel small-molecule PGC-1 $\alpha$ transcriptional regulator with beneficial effects on diabetic $\mathrm{db} / \mathrm{db}$ mice. Diabetes 2013 62 1297-1307. (doi:10.2337/db12-0703)

51 Hoehn KL, Turner N, Swarbrick MM, Wilks D, Preston E, Phua Y, Joshi H, Furler SM, Larance M, Hegarty BD et al. Acute or chronic upregulation of mitochondrial fatty acid oxidation has no net effect on whole-body energy expenditure or adiposity. Cell Metabolism 2010 11 70-76. (doi:10.1016/j.cmet.2009.11.008)

52 Olson DP, Pulinilkunnil T, Cline GW, Shulman GI \& Lowell BB. Gene knockout of Acc2 has little effect on body weight, fat mass, or food intake. PNAS 2010107 7598-7603. (doi:10.1073/pnas.0913492107)

53 Abu-Elheiga L, Matzuk MM, Abo-Hashema KA \& Wakil SJ. Continuous fatty acid oxidation and reduced fat storage in mice lacking acetylCoA carboxylase 2. Science 2001291 2613-2616. (doi:10.1126/science. 1056843)

54 Abu-Elheiga L, Oh W, Kordari P \& Wakil SJ. Acetyl-CoA carboxylase 2 mutant mice are protected against obesity and diabetes induced by high-fat/high-carbohydrate diets. PNAS 2003100 10207-10212. (doi:10.1073/pnas.1733877100)

55 Abu-Elheiga L, Wu H, Gu Z, Bressler R \& Wakil SJ. Acetyl-CoA carboxylase $2^{-/-}$mutant mice are protected against fatty liver under high-fat, high-carbohydrate dietary and de novo lipogenic conditions. Journal of Biological Chemistry 2012287 12578-12588. (doi:10.1074/ jbc.M111.309559)

56 Choi CS, Savage DB, Abu-Elheiga L, Liu Z-X, Kim S, Kulkarni A, Distefano A, Hwang Y-J, Reznick RM, Codella R et al. Continuous fat oxidation in acetyl-CoA carboxylase 2 knockout mice increases total energy expenditure, reduces fat mass, and improves insulin sensitivity. PNAS 2007 104 16480-16485. (doi:10.1073/pnas.0706794104)

57 Cheatham B \& Kahn CR. Insulin action and the insulin signaling network. Endocrine Reviews 199516 117-142. (doi:10.1210/edrv16-2-117)

58 O'Brien RM \& Granner DK. Regulation of gene expression by insulin. Physiological Reviews 199676 1109-1161.

59 Zhao X, Bak S, Pedersen AJT, Jensen ON \& Højlund K. Insulin increases phosphorylation of mitochondrial proteins in human skeletal muscle in vivo. Journal of Proteome Research 201413 2359-2369. (doi:10.1021/ pr401163t)

60 Asmann YW, Stump CS, Short KR, Coenen-Schimke JM, Guo Z, Bigelow ML \& Nair KS. Skeletal muscle mitochondrial functions, mitochondrial DNA copy numbers, and gene transcript profiles in type 2 diabetic and nondiabetic subjects at equal levels of low or high insulin and euglycemia. Diabetes 200655 3309-3319. (doi:10.2337/ db05-1230)

61 Stump CS, Short KR, Bigelow ML, Schimke JM \& Nair KS. Effect of insulin on human skeletal muscle mitochondrial ATP production, protein synthesis, and mRNA transcripts. PNAS 2003100 7996-8001. (doi:10.1073/pnas.1332551100)

62 Karakelides H, Asmann YW, Bigelow ML, Short KR, Dhatariya K, Coenen-Schimke J, Kahl J, Mukhopadhyay D \& Nair KS. Effect of insulin deprivation on muscle mitochondrial ATP production and gene transcript levels in type 1 diabetic subjects. Diabetes 200756 2683-2689. (doi:10.2337/db07-0378)

63 Yerby B, Deacon R, Beaulieu V, Liang J, Gao J \& Laurent D. Insulinstimulated mitochondrial adenosine triphosphate synthesis is blunted in skeletal muscles of high-fat-fed rats. Metabolism: Clinical and Experimental 200857 1584-1590. (doi:10.1016/j.metabol. 2008.06.015)

64 Long YC, Cheng Z, Copps KD \& White MF. Insulin receptor substrates Irs1 and Irs2 coordinate skeletal muscle growth and metabolism via the Akt and AMPK pathways. Molecular and Cellular Biology 201131 430-441. (doi:10.1128/MCB.00983-10)

65 Cheng Z, Guo S, Copps K, Dong X, Kollipara R, Rodgers JT, Depinho RA, Puigserver P \& White MF. Foxo1 integrates insulin signaling with mitochondrial function in the liver. Nature Medicine 200915 1307-1311. (doi:10.1038/nm.2049)

66 Guo S, Copps KD, Dong X, Park S, Cheng Z, Pocai A, Rossetti L, Sajan M, Farese RV \& White MF. The Irs1 branch of the insulin signaling cascade plays a dominant role in hepatic nutrient homeostasis. Molecular and Cellular Biology 200929 5070-5083. (doi:10.1128/MCB.00138-09)

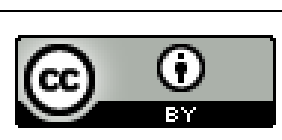

This work is licensed under a Creative Commons Attribution 3.0 Unported License. 
67 Brand MD. The sites and topology of mitochondrial superoxide production. Experimental Gerontology 201045 466-472. (doi:10.1016/j.exger.2010.01.003)

68 Lambert A \& Brand M. Reactive oxygen species production by mitochondria. In Mitochondrial DNA: Methods and Protocols, volume 554, pp 165-181. Ed. JA Stuart. New York, NY, USA: Humana Press, 2009.

69 Boveris A, Oshino N \& Chance B. The cellular production of hydrogen peroxide. Biochemical Journal 1972128 617-630.

70 Paolisso G, Gambardella A, Tagliamonte MR, Saccomanno F, Salvatore T, Gualdiero P, D'Onofrio MV \& Howard BV. Does free fatty acid infusion impair insulin action also through an increase in oxidative stress? Journal of Clinical Endocrinology and Metabolism 1996 81 4244-4248. (doi:10.1210/jcem.81.12.8954022)

71 De Mattia G, Bravi MC, Laurenti O, Cassone-Faldetta M, Armiento A, Ferri C \& Balsano F. Influence of reduced glutathione infusion on glucose metabolism in patients with non-insulin-dependent diabetes mellitus. Metabolism: Clinical and Experimental 199847 993-997. (doi:10.1016/S0026-0495(98)90357-2)

72 Anderson EJ, Lustig ME, Boyle KE, Woodlief TL, Kane DA, Lin C-T, Price JW III, Kang L, Rabinovitch PS, Szeto HH et al. Mitochondrial $\mathrm{H}_{2} \mathrm{O}_{2}$ emission and cellular redox state link excess fat intake to insulin resistance in both rodents and humans. Journal of Clinical Investigation 2009119 573-581. (doi:10.1172/JCI37048)

73 Hoehn KL, Salmon AB, Hohnen-Behrens C, Turner N, Hoy AJ, Maghzal GJ, Stocker R, Van Remmen H, Kraegen EW, Cooney GJ et al. Insulin resistance is a cellular antioxidant defense mechanism. PNAS 2009106 17787-17792. (doi:10.1073/pnas.0902380106)

74 Houstis N, Rosen ED \& Lander ES. Reactive oxygen species have a causal role in multiple forms of insulin resistance. Nature 2006 440 944-948. (doi:10.1038/nature04634)

75 Nakamura S, Takamura T, Matsuzawa-Nagata N, Takayama H, Misu H, Noda H, Nabemoto S, Kurita S, Ota T, Ando H et al. Palmitate induces insulin resistance in H4IIEC3 hepatocytes through reactive oxygen species produced by mitochondria. Journal of Biological Chemistry 2009 284 14809-14818. (doi:10.1074/jbc.M901488200)

76 Lee H-Y, Choi CS, Birkenfeld AL, Alves TC, Jornayvaz FR, Jurczak MJ, Zhang D, Woo DK, Shadel GS, Ladiges W et al. Targeted expression of catalase to mitochondria prevents age-associated reductions in mitochondrial function and insulin resistance. Cell Metabolism 2010 12 668-674. (doi:10.1016/j.cmet.2010.11.004)

77 Chen L, Na R, Gu M, Salmon AB, Liu Y, Liang H, Qi W, Van Remmen $\mathrm{H}$, Richardson A \& Ran Q. Reduction of mitochondrial $\mathrm{H}_{2} \mathrm{O}_{2}$ by overexpressing peroxiredoxin 3 improves glucose tolerance in mice. Aging Cell 20087 866-878. (doi:10.1111/j.1474-9726.2008. 00432.x)

78 Asemi Z, Samimi M, Tabassi Z, Shakeri H \& Esmaillzadeh A. Vitamin D supplementation affects serum high-sensitivity C-reactive protein, insulin resistance, and biomarkers of oxidative stress in pregnant women. Journal of Nutrition 2013143 1432-1438. (doi:10.3945/ jn.113.177550)

79 Fang F, Kang Z \& Wong C. Vitamin E tocotrienols improve insulin sensitivity through activating peroxisome proliferator-activated receptors. Molecular Nutrition \& Food Research 201054 345-352. (doi:10.1002/mnfr.200900119)

80 Kim C-W, Kim B-T, Park K-H, Kim K-M, Lee D-J, Yang S-W \& Joo N-S. Effects of short-term chromium supplementation on insulin sensitivity and body composition in overweight children: randomized, double-blind, placebo-controlled study. Journal of Nutritional Biochemistry 201122 1030-1034. (doi:10.1016/j.jnutbio.2010.10.001)

81 Nguyen D, Hsu JW, Jahoor F \& Sekhar RV. Effect of increasing glutathione with cysteine and glycine supplementation on mitochondrial fuel oxidation, insulin sensitivity, and body composition in older HIV-infected patients. Journal of Clinical Endocrinology and Metabolism 201499 169-177. (doi:10.1210/jc.2013-2376)
82 Rhee Y \& Brunt A. Flaxseed supplementation improved insulin resistance in obese glucose intolerant people: a randomized crossover design. Nutrition Journal 201110 44. (doi:10.1186/1475-2891-10-44)

83 Kim BS, Cha H-N, Kim Y-W, Kim J-Y, Dan J-M \& Park S-Y. Inhibition of lipid infusion-induced skeletal muscle insulin resistance by cotreatment with tempol and glutathione in mice. Journal of Pharmacological Sciences 2009110 370-380. (doi:10.1254/jphs.09046FP)

84 Cao K, Xu J, Zou X, Li Y, Chen C, Zheng A, Li H, Li H, Szeto IM, Shi Y et al. Hydroxytyrosol prevents diet-induced metabolic syndrome and attenuates mitochondrial abnormalities in obese mice. Free Radical Biology \& Medicine 201467 396-407. (doi:10.1016/j.freeradbiomed. 2013.11.029)

85 Jang H-J, Ridgeway SD \& Kim J-A. Effects of the green tea polyphenol epigallocatechin-3-gallate on high-fat diet-induced insulin resistance and endothelial dysfunction. American Journal of Physiology. Endocrinology and Metabolism 2013305 E1444-E1454. (doi:10.1152/ ajpendo.00434.2013)

86 Tomaro-Duchesneau C, Saha S, Malhotra M, Jones M, Labbé A, Rodes L, Kahouli I \& Prakash S. Effect of orally administered $L$. fermentum NCIMB 5221 on markers of metabolic syndrome: an in vivo analysis using ZDF rats. Applied Microbiology and Biotechnology 201498 115-126. (doi:10.1007/s00253-013-5252-8)

87 de Oliveira AM, Rondó PH, Luzia LA, D’Abronzo FH \& Illison VK. The effects of lipoic acid and $\alpha$-tocopherol supplementation on the lipid profile and insulin sensitivity of patients with type 2 diabetes mellitus: a randomized, double-blind, placebo-controlled trial. Diabetes Research and Clinical Practice 201192 253-260. (doi:10.1016/j.diabres.2011.02.010)

88 Hsu C-H, Liao Y-L, Lin S-C, Tsai T-H, Huang C-J \& Chou P. Does supplementation with green tea extract improve insulin resistance in obese type 2 diabetics? A randomized, double-blind, and placebocontrolled clinical trial. Alternative Medicine Review 201116 157-164.

89 Mielgo-Ayuso J, Barrenechea L, Alcorta P, Larrarte E, Margareto J \& Labayen I. Effects of dietary supplementation with epigallocatechin3-gallate on weight loss, energy homeostasis, cardiometabolic risk factors and liver function in obese women: randomised, double-blind, placebo-controlled clinical trial. British Journal of Nutrition 2014111 1263-1271. (doi:10.1017/S0007114513003784)

90 Czernichow S, Vergnaud A-C, Galan P, Arnaud J, Favier A, Faure H, Huxley R, Hercberg S \& Ahluwalia N. Effects of long-term antioxidant supplementation and association of serum antioxidant concentrations with risk of metabolic syndrome in adults. American Journal of Clinical Nutrition 200990 329-335. (doi:10.3945/ajcn.2009.27635)

91 Paglialunga S, van Bree B, Bosma M, Valdecantos MP, AmengualCladera E, Jörgensen JA, van Beurden D, den Hartog GJ, Ouwens DM, Briedé JJ et al. Targeting of mitochondrial reactive oxygen species production does not avert lipid-induced insulin resistance in muscle tissue from mice. Diabetologia 201255 2759-2768. (doi:10.1007/ s00125-012-2626-x)

92 Kubli DA \& Gustafsson ÅB. Mitochondria and mitophagy: the yin and yang of cell death control. Circulation Research 2012111 1208-1221. (doi:10.1161/CIRCRESAHA.112.265819)

93 Ding WX \& Yin XM. Mitophagy: mechanisms, pathophysiological roles, and analysis. Biological Chemistry 2012393 547-564. (doi:10.1515/hsz-2012-0119)

94 Novak I. Mitophagy: a complex mechanism of mitochondrial removal. Antioxidants \& Redox Signaling 201217 794-802. (doi:10.1089/ars.2011.4407)

95 Drew BG, Ribas V, Le JA, Henstridge DC, Phun J, Zhou Z, Soleymani T, Daraei P, Sitz D, Vergnes L et al. HSP72 is a mitochondrial stress sensor critical for parkin action, oxidative metabolism, and insulin sensitivity in skeletal muscle. Diabetes 201463 1488-1505. (doi:10.2337/db130665)

96 Westermann B. Mitochondrial fusion and fission in cell life and death. Nature Reviews. Molecular Cell Biology 201011 872-884. (doi:10.1038/ nrm3013)

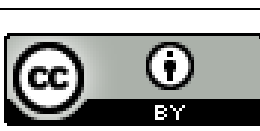

This work is licensed under a Creative Commons Attribution 3.0 Unported License. 
97 Twig G, Hyde B \& Shirihai OS. Mitochondrial fusion, fission and autophagy as a quality control axis: the bioenergetic view. Biochimica et Biophysica Acta 20081777 1092-1097. (doi:10.1016/j.bbabio.2008. 05.001)

98 Cipolat S, de Brito OM, Dal Zilio B \& Scorrano L. OPA1 requires mitofusin 1 to promote mitochondrial fusion. PNAS $2004 \mathbf{1 0 1}$ 15927-15932. (doi:10.1073/pnas.0407043101)

99 Hales KG \& Fuller MT. Developmentally regulated mitochondrial fusion mediated by a conserved, novel, predicted GTPase. Cell 1997 90 121-129. (doi:10.1016/S0092-8674(00)80319-0)

100 Hales KG. The machinery of mitochondrial fusion, division, and distribution, and emerging connections to apoptosis. Mitochondrion 20044 285-308. (doi:10.1016/j.mito.2004.05.007)

101 Zungu M, Schisler J \& Willis MS. All the little pieces - regulation of mitochondrial fusion and fission by ubiquitin and small ubiquitinlike modifier and their potential relevance in the heart. Circulation Journal 201175 2513-2521. (doi:10.1253/circj.CJ-11-0967)

102 Zorzano A, Liesa M \& Palacín M. Role of mitochondrial dynamics proteins in the pathophysiology of obesity and type 2 diabetes. International Journal of Biochemistry \& Cell Biology 200941 1846-1854. (doi:10.1016/j.biocel.2009.02.004)

103 Bach D, Pich S, Soriano FX, Vega N, Baumgartner B, Oriola J, Daugaard JR, Lloberas J, Camps M, Zierath JR et al. Mitofusin-2 determines mitochondrial network architecture and mitochondrial metabolism: a novel regulatory mechanism altered in obesity. Journal of Biological Chemistry 2003278 17190-17197. (doi:10.1074/jbc.M212754200)

104 Pich S, Bach D, Briones P, Liesa M, Camps M, Testar X, Palacín M \& Zorzano A. The Charcot-Marie-Tooth type 2A gene product, Mfn2, up-regulates fuel oxidation through expression of OXPHOS system. Human Molecular Genetics 200514 1405-1415. (doi:10.1093/hmg/ ddi149)

105 Chen H, Vermulst M, Wang YE, Chomyn A, Prolla TA, McCaffery JM \& Chan DC. Mitochondrial fusion is required for mtDNA stability in skeletal muscle and tolerance of mtDNA mutations. Cell 2010141 280-289. (doi:10.1016/j.cell.2010.02.026)

106 Bach D, Naon D, Pich S, Soriano FX, Vega N, Rieusset J, Laville M, Guillet C, Boirie Y, Wallberg-Henriksson H et al. Expression of Mfn2, the Charcot-Marie-Tooth neuropathy type 2A gene, in human skeletal muscle: effects of type 2 diabetes, obesity, weight loss, and the regulatory role of tumor necrosis factor $\alpha$ and interleukin-6. Diabetes 200554 2685-2693. (doi:10.2337/diabetes.54.9.2685)

107 Mingrone G, Manco M, Calvani M, Castagneto M, Naon D \& Zorzano A. Could the low level of expression of the gene encoding skeletal muscle mitofusin-2 account for the metabolic inflexibility of obesity? Diabetologia 200548 2108-2114. (doi:10.1007/s00125005-1918-9)

108 Phielix E, Meex R, Moonen-Kornips E, Hesselink MK \& Schrauwen P. Exercise training increases mitochondrial content and ex vivo mitochondrial function similarly in patients with type 2 diabetes and in control individuals. Diabetologia 201053 1714-1721. (doi:10.1007/s00125-010-1764-2)

109 Rimbert V, Boirie Y, Bedu M, Hocquette JF, Ritz P \& Morio B. Muscle fat oxidative capacity is not impaired by age but by physical inactivity: association with insulin sensitivity. FASEB Journal 200418 737-739. (doi:10.1096/fj.03-1104fje)

110 Toledo FG, Menshikova EV, Ritov VB, Azuma K, Radikova Z, DeLany J \& Kelley DE. Effects of physical activity and weight loss on skeletal muscle mitochondria and relationship with glucose control in type 2 diabetes. Diabetes 200756 2142-2147. (doi:10.2337/db07-0141)

111 Nielsen J, Mogensen M, Vind BF, Sahlin K, Hojlund K, Schroder HD \& Ortenblad N. Increased subsarcolemmal lipids in type 2 diabetes: effect of training on localization of lipids, mitochondria, and glycogen in sedentary human skeletal muscle. American Journal of Physiology. Endocrinology and Metabolism 2010298 E706-E713. (doi:10.1152/ ajpendo.00692.2009)
112 Meex RC, Schrauwen-Hinderling VB, Moonen-Kornips E, Schaart G, Mensink M, Phielix E, van de Weijer T, Sels JP, Schrauwen P \& Hesselink MK. Restoration of muscle mitochondrial function and metabolic flexibility in type 2 diabetes by exercise training is paralleled by increased myocellular fat storage and improved insulin sensitivity. Diabetes 201059 572-579. (doi:10.2337/db09-1322)

113 Dengel DR, Pratley RE, Hagberg JM, Rogus EM \& Goldberg AP. Distinct effects of aerobic exercise training and weight loss on glucose homeostasis in obese sedentary men. Journal of Applied Physiology 199681 318-325. (doi:10.1097/00005768)

114 Niskanen L, Uusitupa M, Sarlund H, Siitonen O, Paljärvi L \& Laakso M. The effects of weight loss on insulin sensitivity, skeletal muscle composition and capillary density in obese non-diabetic subjects. International Journal of Obesity and Related Metabolic Disorders 1996 20 154-160.

115 Weiss EP, Racette SB, Villareal DT, Fontana L, Steger-May K, Schechtman KB, Klein S \& Holloszy JO. Improvements in glucose tolerance and insulin action induced by increasing energy expenditure or decreasing energy intake: a randomized controlled trial. American Journal of Clinical Nutrition 200684 1033-1042.

116 Larson-Meyer DE, Heilbronn LK, Redman LM, Newcomer BR, Frisard MI, Anton S, Smith SR, Alfonso A \& Ravussin E. Effect of calorie restriction with or without exercise on insulin sensitivity, $\beta$-cell function, fat cell size, and ectopic lipid in overweight subjects. Diabetes Care 200629 1337-1344. (doi:10.2337/dc05-2565)

117 Civitarese AE, Carling S, Heilbronn LK, Hulver MH, Ukropcova B, Deutsch WA, Smith SR \& Ravussin E. Calorie restriction increases muscle mitochondrial biogenesis in healthy humans. PLoS Medicine 20074 e76. (doi:10.1371/journal.pmed.0040076)

118 Kitada M, Kume S, Takeda-Watanabe A, Tsuda S, Kanasaki K \& Koya D. Calorie restriction in overweight males ameliorates obesity-related metabolic alterations and cellular adaptations through anti-aging effects, possibly including AMPK and SIRT1 activation. Biochimica et Biophysica Acta 20131830 4820-4827. (doi:10.1016/j.bbagen.2013. 06.014)

119 Schenk S, McCurdy CE, Philp A, Chen MZ, Holliday MJ, Bandyopadhyay GK, Osborn O, Baar K \& Olefsky JM. Sirt1 enhances skeletal muscle insulin sensitivity in mice during caloric restriction. Journal of Clinical Investigation 2011121 4281-4288. (doi:10.1172/ JCI58554)

120 Lagouge M, Argmann C, Gerhart-Hines Z, Meziane H, Lerin C, Daussin F, Messadeq N, Milne J, Lambert P, Elliott P et al. Resveratrol improves mitochondrial function and protects against metabolic disease by activating SIRT1 and PGC-1 $\alpha$. Cell 2006127 1109-1122. (doi:10.1016/j.cell.2006.11.013)

121 Baur JA, Pearson KJ, Price NL, Jamieson HA, Lerin C, Kalra A, Prabhu VV, Allard JS, Lopez-Lluch G, Lewis K et al. Resveratrol improves health and survival of mice on a high-calorie diet. Nature 2006444 337-342. (doi:10.1038/nature05354)

122 Milne JC, Lambert PD, Schenk S, Carney DP, Smith JJ, Gagne DJ, Jin L, Boss O, Perni RB, Vu CB et al. Small molecule activators of SIRT1 as therapeutics for the treatment of type 2 diabetes. Nature $2007 \mathbf{4 5 0}$ 712-716. (doi:10.1038/nature06261)

123 Mercken EM, Mitchell SJ, Martin-Montalvo A, Minor RK, Almeida M, Gomes AP, Scheibye-Knudsen M, Palacios HH, Licata JJ, Zhang Y et al. SRT2104 extends survival of male mice on a standard diet and preserves bone and muscle mass. Aging Cell 201413 787-796. (doi:10.1111/acel.12151)

124 Minor RK, Baur JA, Gomes AP, Ward TM, Csiszar A, Mercken EM, Abdelmohsen K, Shin Y-K, Canto C, Scheibye-Knudsen M et al. SRT1720 improves survival and healthspan of obese mice. Scientific Reports 20111 70. (doi:10.1038/srep00070)

125 Mookerjee SA, Divakaruni AS, Jastroch M \& Brand MD. Mitochondrial uncoupling and lifespan. Mechanisms of Ageing and Development 2010 131 463-472. (doi:10.1016/j.mad.2010.03.010)

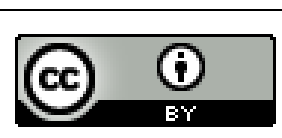

This work is licensed under a Creative Commons Attribution 3.0 Unported License. 
126 Tao H, Zhang Y, Zeng X, Shulman GI \& Jin S. Niclosamide ethanolamine-induced mild mitochondrial uncoupling improves diabetic symptoms in mice. Nature Medicine 201420 1263-1269. (doi:10.1038/nm.3699)

127 Adjeitey CN, Mailloux RJ, deKemp RA \& Harper ME. Mitochondrial uncoupling in skeletal muscle by UCP1 augments energy expenditure and glutathione content while mitigating ROS production. American Journal of Physiology. Endocrinology and Metabolism 2013305 E405-E415. (doi:10.1152/ajpendo.00057.2013)

128 Perry RJ, Kim T, Zhang X-M, Lee H-Y, Pesta D, Popov VB, Zhang D, Rahimi Y, Jurczak MJ, Cline GW et al. Reversal of hypertriglyceridemia, fatty liver disease, and insulin resistance by a liver-targeted mitochondrial uncoupler. Cell Metabolism 201318 740-748. (doi:10.1016/j.cmet.2013.10.004)

129 Tainter ML, Stockton AB \& Cutting WC. Use of dinitrophenol in obesity and related conditions. Final report. Journal of the American Medical Association 1935105 332-336. (doi:10.1001/jama.1935. 02760310006002)

130 Antonenko YN, Avetisyan AV, Cherepanov DA, Knorre DA, Korshunova GA, Markova OV, Ojovan SM, Perevoshchikova IV, Pustovidko AV, Rokitskaya TI et al. Derivatives of rhodamine 19 as mild mitochondria-targeted cationic uncouplers. Journal of Biological Chemistry 2011286 17831-17840. (doi:10.1074/jbc.M110.212837)

131 Lou PH, Hansen BS, Olsen PH, Tullin S, Murphy MP \& Brand MD. Mitochondrial uncouplers with an extraordinary dynamic range. Biochemical Journal 2007407 129-140. (doi:10.1042/BJ20070606)

132 Severin FF, Severina II, Antonenko YN, Rokitskaya TI, Cherepanov DA, Mokhova EN, Vyssokikh MY, Pustovidko AV, Markova OV, Yaguzhinsky LS et al. Penetrating cation/fatty acid anion pair as a mitochondria-targeted protonophore. PNAS 2010107 663-668. (doi:10.1073/pnas.0910216107)

133 Dong H, Wang N, Zhao L \& Lu F. Berberine in the treatment of type 2 diabetes mellitus: a systemic review and meta-analysis. Evidence-Based
Complementary and Alternative Medicine 20122012591654. (doi:10.1155/2012/591654)

134 Lee YS, Kim WS, Kim KH, Yoon MJ, Cho HJ, Shen Y, Ye JM, Lee CH, Oh WK, Kim CT et al. Berberine, a natural plant product, activates AMP-activated protein kinase with beneficial metabolic effects in diabetic and insulin-resistant states. Diabetes 200655 2256-2264. (doi:10.2337/db06-0006)

135 Turner N, Li JY, Gosby A, To SW, Cheng Z, Miyoshi H, Taketo MM, Cooney GJ, Kraegen EW, James DE et al. Berberine and its more biologically available derivative, dihydroberberine, inhibit mitochondrial respiratory complex I: a mechanism for the action of berberine to activate AMP-activated protein kinase and improve insulin action. Diabetes 200857 1414-1418. (doi:10.2337/db07-1552)

136 Eid HM, Martineau LC, Saleem A, Muhammad A, Vallerand D, Benhaddou-Andaloussi A, Nistor L, Afshar A, Arnason JT \& Haddad PS Stimulation of AMP-activated protein kinase and enhancement of basal glucose uptake in muscle cells by quercetin and quercetin glycosides, active principles of the antidiabetic medicinal plant Vaccinium vitis-idaea. Molecular Nutrition \& Food Research 201054 991-1003. (doi:10.1002/mnfr.200900218)

137 Brunmair B, Staniek K, Gras F, Scharf N, Althaym A, Clara R, Roden M, Gnaiger E, Nohl H, Waldhausl W et al. Thiazolidinediones, like metformin, inhibit respiratory complex I: a common mechanism contributing to their antidiabetic actions? Diabetes 200453 1052-1059. (doi:10.2337/diabetes.53.4.1052)

138 Owen MR, Doran E \& Halestrap AP. Evidence that metformin exerts its anti-diabetic effects through inhibition of complex 1 of the mitochondrial respiratory chain. Biochemical Journal 2000348 607-614. (doi:10.1042/0264-6021:3480607)

139 Huang SL, Yu RT, Gong J, Feng Y, Dai YL, Hu F, Hu YH, Tao YD \& Leng Y. Arctigenin, a natural compound, activates AMP-activated protein kinase via inhibition of mitochondria complex I and ameliorates metabolic disorders in ob/ob mice. Diabetologia 2012 55 1469-1481. (doi:10.1007/s00125-011-2366-3)

Received in final form 6 November 2014

Accepted 10 November 2014 http://www.endocrineconnections.org

DOI: 10.1530/EC-14-0092 (c) 2015 The authors Published by Bioscientifica Ltd

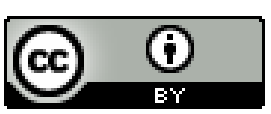

This work is licensed under a Creative Commons Attribution 3.0 Unported License. 